\title{
El audiovisual como medio sociocomunicativo: hacia una antropología audiovisual performativa
}

\section{José Manuel Vidal-Gálvez ${ }^{1}$ Anastasia Téllez-Infantes ${ }^{2}$}

Recibido: 2015-08-09

Enviado a pares: 2015-08-09
Aprobado por pares: 2015-09-09

Aceptado: 2015-09-11

DOI: 10.5294/pacla.2016.19.2.9

Para citar este artículo / To reference this article / Para citar este artigo

Vidal-Gávez, J. M. \& Téllez-Infantes, A. (Junio de 2016). El audiovisual como medio sociocomunicativo: hacia una antropología audiovisual performativa. Palabra Clave, 19(2), 556-580. DOI: 10.5294/pacla.2016.19.2.9

\section{Resumen}

Los recursos audiovisuales como vehículo de comunicación y representación del arte aplicados a la investigación social permiten fomentar un tipo de ciencia que vuelve su mirada más allá del mero diagnóstico científico. Posibilitan devolver el producto final empaquetado en un lenguaje sencillo y accesible, y reconocen, como principal objetivo, el retorno de sus conclusiones al ámbito social en el que se generó como vía hacia la catalización dialéctica y performativa del hecho social y comunicativo. En este texto, presentamos, a partir de trabajos empíricos realizados en España y en Ecuador, la viabilidad de la antropología audiovisual como medio para llevar a cabo una ciencia implicada con el colectivo representado y favorecedora del cambio social.

\footnotetext{
Universidad Miguel Hernández de Elche. España. pzazen@gmail.com

Universidad Miguel Hernández de Elche. España. atellez@umh.es
} 


\section{Palabras clave}

Audiovisual; antropología; Ecuador; arte; documental; comunicación (Fuente: Tesauro de la Unesco).

\section{The Audiovisual Medium as Socio-communicative: Towards a Performative Visual Anthropology}

\section{Abstract}

Audiovisual resources as a vehicle of communication and representation of art applied to social research would foster a type of science that goes beyond mere scientific diagnostic at a glance. Making it possible, return the final packaging product in a simple and accessible language, and recognize, the main objective, the return on its findings to the social environment in which it was created as a way for dialectics and performative catalyst of social and communicative fact. In this paper we present, based on empirical studies in Spain and in Ecuador, the viability of audiovisual anthropology as a means to conduct a science involved with the collective, depicted favorable and social change.

\section{Keywords}

Audiovisual; anthropology; Ecuador; art; documentary; communication (Source: Unesco Thesaurus). 


\section{0 audiovisual como meio sociocomunicativo: rumo a uma antropologia audiovisual perfomativa}

\section{Resumo}

Os recursos audiovisuais como veículo de comunicação e representação da arte aplicados à pesquisa social permitem fomentar um tipo de ciência que volta seu olhar para mais além do mero diagnóstico científico. Possibilitam devolver o produto final embalado numa linguagem simples e acessível, e reconhecem, como principal objetivo, o retorno de suas conclusões ao âmbito social no qual foi gerado como via à catalisação dialética e perfomativa do ato social e comunicativo. Neste texto, apresentamos, a partir de trabalhos empíricos realizados na Espanha e no Equador, a viabilidade da antropologia audiovisual como meio para realizar uma ciência implicada com o coletivo representado e favorecedora da mudança social.

\section{Palavras-chave}

Audiovisual; antropologia; Equador; arte; documentário; comunicação (Fonte: Tesauro da Unesco). 


\section{Introducción}

En un contexto histórico, social y económico como el actual se hace sumamente necesario para docentes e investigadores universitarios, y en especial para los científicos sociales, enfocar la investigación de modo crítico y con un doble objetivo: la transferencia de resultados y la implicación de la sociedad con su participación activa en pro de la práctica transformadora y el cambio social.

Aquí es donde encontramos una gran oportunidad para la antropología, el periodismo, el cine y el arte. Una combinación, una interrelación que permite realizar una ciencia con un nuevo "para qué" y "para quién", una ciencia comprometida. Nos referimos, en concreto, a una antropología, la audiovisual, que se entienda a sí misma como herramienta de cambio social, que traslade su horizonte de sentido, que abandone la idea de ser un mero depósito de conocimiento y se instale en una praxis donde el objetivo sean aquellos con los que se interactúa.

De la antropología sustraemos su esencia: la etnografía, un método que invita a profundizar en el conocimiento cultural de los colectivos humanos. Del periodismo y la comunicación, en general, su enfoque divulgativo. Del arte aplicado al cine, su capacidad de contextualizar, de emocionar, de empatizar con el espectador y su libertad para hacerlo partícipe de un mundo al que nunca pertenecería si no fuera por la magia del audiovisual.

Se trata de crear una argamasa de varios métodos a fin de crear un procedimiento útil y funcional para la antropología audiovisual y así poder generar un producto analizable fruto de una negociación entre la intención del autor, el sujeto representado, su contexto y la audiencia.

Esta investigación gira en torno a la viabilidad de la antropología audiovisual como medio sociocomunicativo que permita desarrollar una ciencia implicada con el colectivo representado. Para ello, nos vemos en la necesidad de ampliar los márgenes de una subdisciplina que tradicionalmente ha entablado un combate directo entre sus partes fundamentales: el cine y la antropología. 
$\mathrm{Al}$ intentar llevar a cabo una antropología audiovisual comprometida, estamos obligados a modificar al receptor de nuestro trabajo y a realizarnos la siguiente pregunta: ¿una ciencia para quién? Evidentemente, no son los únicos ni principales destinatarios un círculo endogámico de eruditos, sino el mismo colectivo con el que se quiere interactuar, y quizá la sociedad en general. Con esta premisa, es insoslayable entrar en el ámbito de la divulgación. Si pretendemos una respuesta en contextos sociales alejados del contexto universitario, debemos servirnos de estrategias narrativas que faciliten la comprensión del texto fílmico para lograr, así, la completa empatía por parte del espectador.

Los tiempos, el tratamiento de las escenas, el montaje, el sonido extradiegético, los recursos informáticos que permiten un control absoluto sobre la imagen; en definitiva, el lenguaje audiovisual se erige en el medio más adecuado para acercar nuestro discurso a la calle. Para todo ello, necesitamos desligarnos de las ataduras que tradicionalmente han rodeado a la antropología audiovisual. Estamos obligados a entenderla como "otra forma de hacer antropología" con recursos propios capaz, por sí misma, de interpretar el texto social. En esta línea, MacDougal defendía "que el cine etnográfico no es [solo] una forma especial de antropología donde el investigador utiliza el cine como una herramienta para mostrar lo que él ya ha incorporado a su conocimiento antes del momento de filmación". En otras palabras, "que el cine etnográfico, su producción y su recepción, es otra forma de antropología que tiene sus propios métodos y praxis" (citado en Stoehrel, 2003, p. 78).

De las tensiones entre las que se mueve el documental etnográfico, destacamos dos de los ejes: las dicotomías arte/ciencia y objetividad/subjetividad. Pese a que no afecta exclusivamente a la antropología audiovisual, para nuestra investigación resulta imprescindible añadir un eje más, aquel que entronca con la dirección del conocimiento: nos referimos al binomio academia/espacio público.

\section{Un conocimiento de ida y vuelta}

Nos vemos en la necesidad de romper con el recorrido tradicional que adopta el conocimiento en antropología. Una dirección que surge desde un ám- 
bito teórico, sobrevuela la realidad y retorna de nuevo como una paloma mensajera a su supuesto lugar de origen: la universidad.

Este texto pretende ir en la línea que concibe el conocimiento antropológico como una vía hacia la generación del cambio social, desde lo que denominan Canals y Cardús "el carácter dialógico y performativo del cine etnográfico" (2010, p. 1). En este caso, no buscamos como fin retornar hacia un conocimiento académico, sino reubicar su objetivo traspasando las fronteras del puro conocimiento. Como defienden algunos autores:

Más allá del simple diagnóstico, la práctica antropológica debe tener un componente metodológico que le permita convertirse en una forma de "agenciamiento" social por medio del cual se provoquen, susciten, inciten, propicien nuevas posibilidades de pensarnos, de pensar el entorno, la sociedad, el país (Caicedo, 2003, p. 178).

Antropólogos como Gimeno (2008), en lo que denomina "antropología de orientación pública", insta a fijar nuestra mirada hacia el espacio público e invita al antropólogo a inmiscuirse hasta el punto de ser parte del cambio.

La pregunta que nos hacemos es la siguiente: ¿qué tipo de ciencia queremos? y ¿dirigida a quién? En un contexto internacional como el hoy, los científicos no deben ni pueden mantener una visión aséptica de una ciencia per se, mucho menos las ciencias sociales, y en especial la antropología, y aún más la antropología audiovisual.

[...] preguntarse y contestarse en torno al propósito de "hacer ciencia": ¿para qué? y ¿para quién? Pues estos interrogantes están presentes e inciden en las prácticas de los investigadores, de tal manera que se convierten un problema ético-político de su actuar. $Y$ en este mundo dominado por el capitalismo neoliberal —indica nuestro autor- es vigente la disyuntiva que planteara Antonio Gramsci a propósito de su antinomia del papel de los intelectuales: ex parte populi (orgánicos 0 al servicio de los movimientos populares) 0 ex parte principi (al servicio del capital). Como aclaró Gillberto, no se trata de una postura maniquea de "buenos" versus "malos", sino de tomar posición y conciencia de su condición y de su accionar en una situación actual única y grave: de exacerbación y agravamiento de 
las contradicciones y lucha de clases y de crisis y colapso civilizatorio (Adame, 2010, p. 2).

¿Hemos de aceptar la máxima de que el antropólogo audiovisual debe ser un mero testigo de lo que filma y que no debe inmiscuirse en la realidad? Esta pregunta remite a la idea de Gramsci (1984) en la que el intelectual sirve de justificación teórica al sistema mundo desde la atalaya incuestionable del discurso científico.

\section{Narratividad: más allá del lenguaje críptico}

El objetivo, sin duda, es reorientar la práctica antropológica creando un trasvase de información entre el diagnóstico académico y el ámbito social. Es aquí donde el lenguaje audiovisual se erige en una vía de agenciamiento por parte de los actores sociales, ya que posibilita una rápida compresión del texto apoyado por la empatía que genera la capacidad de transmisión de las emociones. Permite a su vez aglutinar frente a un mismo discurso a un amplio grupo de personas, lo cual contribuye a abrir diálogos que desatomizan nuestras realidades y apoyan el empoderamiento colectivo. Para ello, es necesario acoger de buen grado las técnicas que requiere el lenguaje audiovisual para manifestarse sin ataduras.

Si partimos de que la narración en el cine viene determinada no solo por la historia que se cuenta sino por los mecanismos con los que se presenta: encuadre, angulación, tipo de plano, continuidad, sonido extradiegético o no, etcétera, resulta del todo imposible desligar narración de demostración o explicación. $\mathrm{O}$ dicho de otro modo: ¿sería posible demostrar o explicar cualquier hecho social con la escritura si no seleccionáramos el material previo, si no construyéramos elipsis narrativas, en definitiva, ¿se puede demostrar o explicar algo con cualquier tipo de lenguaje si no empleamos sus propias herramientas?

Ejemplos que demuestran que esta afirmación no se ajusta a la realidad lo vemos en las obras de Dennis O’Rourke o Timothy Asch. Este último llega a afirmar: 


\begin{abstract}
Estoy atrapado entre la ficción y la realidad etnográfica, pues sé que no hay nada que semeje la realidad etnográfica, y que todo es relativo [...] Una buena definición del cine etnográfico es que resulta aburrido, y no hay necesidad de que sea así. Debemos aprender del cine con función narrativa cómo contar mejor una historia, haciendo también justicia a la gente que estudiamos. Idealmente el tipo de historia que contamos debía ser su historia, no la nuestra. De todos modos debe comunicar, y además, el ser aburrido no es uno de los caracteres definitorios de la comunicación [...]. Creo que la tendencia del cine etnográfico es el poder hacer que la gente hable por sí misma sobre sus 4 propias inquietudes, sobre lo que vemos que hacen y lo que filmamos de ellos (Asch, 1992, pp. 2-5).
\end{abstract}

Es precisamente en las dicotomías descripción/narración, realismo/ creación, donde radica la mayor parte de las discusiones sobre lo que es o no propio de la etnografía audiovisual.

Heider (2009) señala que lo que define a un filme etnográfico es su grado de comprensión etnográfica. Volvemos a la pregunta de cómo es posible la comprensión de un texto fílmico sin el empleo de sus recursos lingüísticos. Ruby afirma de Heider que "sugirió que prácticamente todo film sobre el ser humano puede ser considerado como etnográfico” (2007, p. 14).

Al hacer un simple paralelismo con el lenguaje escrito, se ve con toda claridad la futilidad de la discusión del empleo de los mecanismos narrativos que posee el audiovisual. ¿Se discute con tanto ahínco los recursos retóricos/lingüísticos del lenguaje escrito? ¿Alguien pone en duda que a la hora de redactar un trabajo de campo es necesario la selección de datos? ¿ No es esto una forma de montaje? ¿No hay detrás de este intento de refrenar lo puramente cinematográfico una obsesiva pretensión hacia la objetividad?

La escritura, la fotografía, el cine 0 el vídeo son técnicas de registro de la experiencia, y los efectos de mediación no pueden evitarse, pero se pueden reconocer y no siempre juegan en contra. Al contrario, tienen un papel importante a la hora de describir y de analizar la producción de imágenes desde una perspectiva antropológica, ya que no estudiamos fenómenos físicos o biológicos, sino la realidad social y cultural —una realidad intersubjetiva, mediada por la comunicación simbólica-, en la cual la emotividad, la narratividad y los efectos de comunicación tienen un papel esencial (Ardèvol, 2004, pp. 24-25). 
Por tanto, debemos afirmar que "en toda narrativa el vehículo es el lenguaje articulado, en la imagen el vehículo es la narrativa fílmica" (Dufuur, 2010, p. 319).

En este sentido, y para aceptar estas afirmaciones, necesitamos la convergencia de las diferentes áreas de conocimiento. Necesitamos los mecanismos del lenguaje audiovisual que nos proporciona el arte aplicado al cine en comunión con las metodologías propias de la antropología.

Como Wallerstein (1999) deja entrever, debemos dejar de delimitar los márgenes de las disciplinas abogando por lo transdisciplinar para encontrar nuevos métodos que puedan aplicarse sin peligro de fragmentación de las realidades sociales. Necesitamos desligarnos del útero eurocentrista, del sistema mundo capitalista donde la intervención y, más aún, el cambio son nociones ubicadas en el margen. En nuestro caso, la convergencia de las disciplinas viene implícita en nuestra propia formación como periodistas, comunicadores, realizadores audiovisuales y antropólogos.

\section{La "realidad" en la mirada}

Este modo de "practicar" el quehacer científico remite a otro de los ejes: objetivo/subjetivo, dos planteamientos opuestos de acercamiento a la realidad que conviven paralelamente y que influyen de manera notable a la hora de enfrentar un proyecto audiovisual antropológico.

Por un lado, se mantiene la postura de aquellos que perciben la realidad como algo ajeno al ser humano y que, para ser captado, no requiere la mínima intervención del investigador. En este caso, y desde un punto de vista de la metodología audiovisual, se presupone la no distorsión del aparataje cinematográfico en el lugar de grabación, se obvia la selección de espacios y situaciones que implica el mismo encuadre, se obliga a la no utilización del sonido extradiegético, se promueve la fijación de la cámara sin el empleo de diferentes ángulos y encuadres y se limita al máximo el uso del montaje. En palabras de una experta antropóloga audiovisual:

Un film etnográfico de documentación científica debe satisfacer los siguientes requerimientos: unidad de lugar, tiempo, grupo y acción, 
conjuntamente con una estricta obediencia a la cronología de la acción en su versión final. La manipulación artificial en la filmación y en la edición no está permitida. Un filme científico también debe rechazar las escenas actuadas (citado en Banks, 1992, p. 119). Esta posición estricta en la utilización del cine para hacer ciencia supone el rechazo a todo recurso estético o narrativo y una clara división entre "ciencia" y "arte", de manera que la producción del conocimiento científico es una cosa y su difusión; en este caso a partir de la producción documental, es otra. La filmación no manipulada es fiel al "hecho" que registra, cualquier alteración supone "ficcionalizar" la realidad, deslizarse hacia la subjetividad, huir de la objetividad (Ardévol, 2008, p. 74).

Con toda esta visión coercitiva de los recursos audiovisuales, se pretende captar aquella supuesta objetividad que permanece ahí fuera como un ente ajeno a la visión del investigador/realizador y de las propias personas filmadas.

En las antípodas de este enfoque, nos encontramos con el posicionamiento de quienes consideran que la realidad, si es tal, nace de la propia interacción de subjetividades, y conciben la antropología audiovisual como una subdisciplina que se construye formalmente de acuerdo con los recursos lingüísticos del lenguaje audiovisual, que permite la interpretación subjetiva a través del empleo del montaje, las tomas y todo tipo de recursos que posibilita captar la realidad desde la propia realidad vivida, sentida y percibida.

\begin{abstract}
Nuestra vivencia del mundo que nos rodea se basa en lo que vemos, olimos, oímos, tocamos, sentimos, gustamos, pensamos, recordamos e imaginamos. Para desarrollar una "antropología de la experiencia" como por ejemplo MacDougal trata de hacerlo, no basta entonces con combinar la palabra con la imagen, sino que es necesario buscar una forma de filmación y de montaje que pueda mostrar la complejidad de esas experiencias. Se trata de traducir olores, gustos y sensaciones de roce, a imágenes. Se trata de desarrollar una forma de conocimiento corporal (Stoehrel, 2003, p. 81).
\end{abstract}

Es necesario superar definitivamente el paradigma positivista que entiende que la realidad social es asible en la medida en que se instala al margen de nuestra percepción, de nuestra subjetividad. Para ello, resulta im- 
prescindible el empleo de la narrativa audiovisual y la ficción. Como bien advierte Ardévol:

La potencia de la cámara no está en la objetividad del medio, sino en el reconocimiento de nuestra mirada en la imagen y, por tanto, en el redescubrimiento de sus pautas y regularidades, de sus subjetividades compartidas y desiguales. La antropología no estudia el mundo físico, sino sus representaciones; la actividad simbólica de la mente humana. Diez cámaras de vídeo automáticas registrando sin interrupción una corrida de toros dan menos información sobre el contexto de la interacción que una sola cámara movida por un ser inteligente y sensible, aunque no tenga ni idea de lo que es una corrida de toros $(1998$, p. 3).

\section{Dos experimentos audiovisuales: El 15-M y la plaza de Los Ponchos}

Nos remontamos a 2011 cuando, involuntariamente, se germina la idea básica que conducirá este trabajo. En esa fecha, surge el movimiento del 15-M, que tuvo su reflejo entre otras muchas ciudades en Elche. ${ }^{3}$ Era un fenómeno contestatario de respuesta ciudadana ante las repercusiones de la crisis económica y social, que se extendió por todas y cada una de las localidades de la geografía española.

El 15-M es un movimiento ciudadano que nació tras la manifestación del 15 de mayo de 2011, que dio lugar a que unas cuarenta personas acampasen de forma espontánea en la simbólica plaza de la Puerta del Sol. ${ }^{4}$ A causa de este acto, las manifestaciones se sucedieron en toda España. Las máximas que empujaron la filosofía del movimiento era la de promover una democracia participativa donde la ciudadanía fuese sea copartícipe de las decisiones del Gobierno. Esta propuesta desliga al 15-M del bipartidismo imperante hasta ese momento representado por el PSOE (Partido Socialista Obrero Español) y el PP (Partido Popular). Asimismo, las críticas se dirigían hacia el modelo económico neoliberal entendiéndolo como germen del incremento de las desigualdades sociales.

3 Elche es una ciudad de la provincia de Alicante en la Comunidad Valenciana (España), con una población en 2014 de 228.647 habitantes (Instituto Nacional de Estadística, s. f.).

4 La Puerta del Sol es una plaza de Madrid, donde se encuentra el denominado Kilómetro Cero desde donde se inicia el kilometraje de las carreteras españolas. 
Aquí vimos una oportunidad para comenzar a poner a prueba nuestra visión de la antropología audiovisual y al mismo tiempo aportar nuestro granito de arena a un acontecimiento al que ya se considera histórico. Así nos fuimos y participamos de este movimiento del 15-M en nuestra ciudad, Elche.

A medida que convivíamos con nuestra cámara, nos fuimos dando cuenta de que todos aquellos datos que íbamos recabando daban lugar a un producto que debía ser compartido. Así, una vez editado el material, un documental que denominamos Elche toma la calle, ${ }^{5}$ decidimos proyectarlo en la misma plaza del centro de Elche desde donde partían todas las acciones del 15-M en nuestra ciudad. La respuesta nos superó; aún más, nos conmovió: el colectivo afrontaba en ese momento profundas discrepancias en cuanto a los contenidos de sus propuestas, lo cual acabó degenerando en la disgregación del propio grupo de personas del 15-M ilicitano en diversos subgrupos reorganizados con diferentes propuestas. Entre las discrepancias que se daban estaba la derivación o no del movimiento asambleario hacia una propuesta electoral concreta que se plasmara en la formación de un partido político. Pero más allá de las discusiones de contenido, las divergencias se daban en las diferencias personales fruto, quizá, de la sobrecarga de trabajo de los individuos sobre los que recaían, de forma totalmente azarosa, la movilización de las acciones. ${ }^{6}$

Cuando acabó la proyección, las partes en conflicto se levantaron y se fundieron en un abrazo. Como aseguraría posteriormente una de las movilizadoras principales del movimiento en Elche: "Después de vernos allí en la pantalla... fue como si aquello que estábamos viendo nos hiciera más conscientes de lo que habíamos logrado en común. El árbol nos impedía ver el bosque".

El bosque al que hace mención esta informante no es más que una metáfora del día a día. La vorágine diaria obstaculizaba al colectivo tomar

5 Este documental se puede ver completo en https://www.youtube.com/watch?t=37\&v=H6dgg29700g

6 Hemos de tener en cuenta que el movimiento 15-M tiene un carácter asambleario donde la toma de decisiones es conjunta y no existe una cabeza visible que represente y ejecute lo elegido y votado por el colectivo. Aun así, la puesta en marcha de las acciones terminaban recayendo sobre individuos que, de modo desinteresado, se erigían en dinamizadores principales del movimiento. 
conciencia de su propia fuerza como tal. El audiovisual confirmó su capacidad ya no solo empática que conduce hacia la movilización de las emociones, sino la de sustraer los acontecimientos y reorganizarlos en una estructura lingüística que rememora lo acontecido y que reconvierte lo sucedido reduciéndolo a su denominador común, obviando lo anecdótico.

Sentimos que habíamos superado con creces nuestro objetivo de devolver a la calle lo que había sido siempre de la calle. Pero si en un primer momento nuestra intención fue movida por una mera cuestión ética, a la vista de los resultados obtenidos, comprendimos que quizá se podría enfocar nuestro trabajo hacia la búsqueda del potencial del audiovisual como refuerzo identitario de un colectivo, como catalizador de identidad social.

Si bien aquel proyecto concluyó en la misma plaza de Elche donde nació, la imagen de aquel grupo reconstruido se mantuvo latente como base para posteriores investigaciones. Sin embargo, para poder generalizar esta idea, pensamos que debía ser probada en un contexto ajeno en el que se desarrolló el documental sobre el 15-M ilicitano.

Solo tuvimos que esperar un año para que el azar nos presentara la posibilidad de llevar nuestras ideas a un marco cultural distinto.

Por diversas circunstancias personales, en 2012 surge la posibilidad de vivir una temporada en Otavalo, ciudad en el corazón de los Andes ecuatorianos. Inmediatamente, planea la idea de llevar a otro contexto la experiencia vivida en el movimiento $15-\mathrm{M}$. Tras un periodo de varios meses documentándonos sobre la zona, decidimos centrarnos en un emblema identitario del pueblo kichwa-otavaleño y del propio Estado ecuatoriano: la plaza de Los Ponchos.

El planteamiento es el siguiente: a mediados de 2012, durante un periodo de cuatro meses, realizamos el trabajo de campo y la grabación en la plaza de Los Ponchos. Al volver a España, dedicamos alrededor de un año a la edición y al análisis de los datos recabados. En 2014, volvimos a Ecuador con el resultado de nuestro trabajo para analizar los efectos sobre la co- 
munidad del audiovisual resultante: La ventana de los Andes, ${ }^{7}$ dando lugar a otro documental, Runas, que recaba el proceso de generación de debates en torno a las proyecciones, así como un acercamiento a la cultura kichwaotavaleña y su relación con los problemas de la plaza. La importancia de la plaza de Los Ponchos estriba en el hecho de que se erige en el símbolo de apropiación del espacio urbano por parte del indígena kichwa de Otavalo, tradicionalmente relegado a la periferia rural, ya que la ciudad ha sido el territorio de poder del hombre blanco/mestizo (figuras 1 y 2 ).

Figura 1. Plaza de Los Ponchos (Otavalo, Ecuador, 2014)

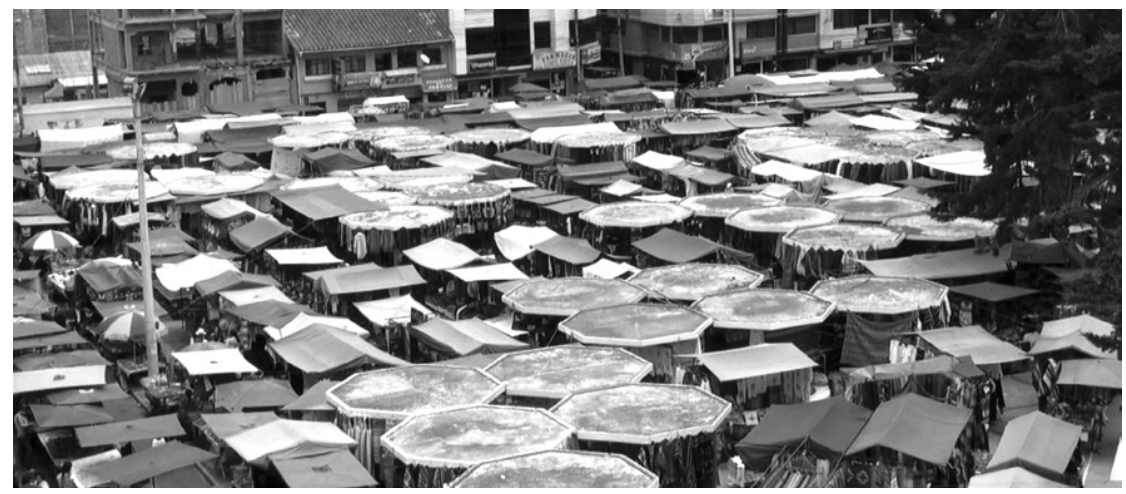

Figura 2. Proyección del documental en la plaza de Los Ponchos (Otavalo, Ecuador, 2014)

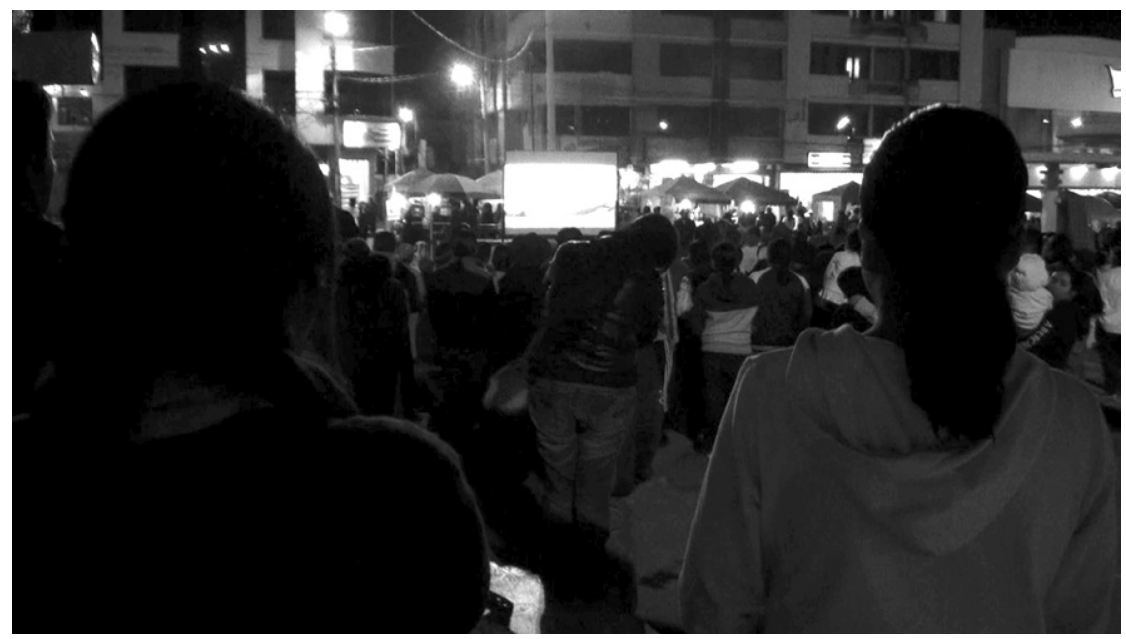

7 Véase el tráiler en http://pzazen.wix.com/laventanadelosandes 
Sin embargo, un lugar tan emblemático sufre de una degradación que afecta a lo más profundo de la identidad kichwa: la dejadez por parte de las autoridades ha dado lugar a la pérdida progresiva de la artesanía en favor de productos industriales procedentes de diversos países. Esta falta de atención por parte de los gobernantes se ve reflejada en el deterioro de las infraestructuras que complica el trabajo de los comerciantes de la plaza. Por otra parte, es necesario señalar que existen unas estructuras de poder que se generan en la plaza relacionadas con la existencia de varias asociaciones en conflicto que agrupan a diferentes artesanos y vendedores. Todas ellas con un denominador común: la falta de representatividad de sus asociados (figura 3). Taly como ellos aseguran: "hay una decena de asociaciones dentro de la plaza y todas ellas buscan el poder para sí mismas”.

\section{Figura 3. Comerciante de la plaza en su turno de palabra (Otavalo, Ecuador, 2014)}

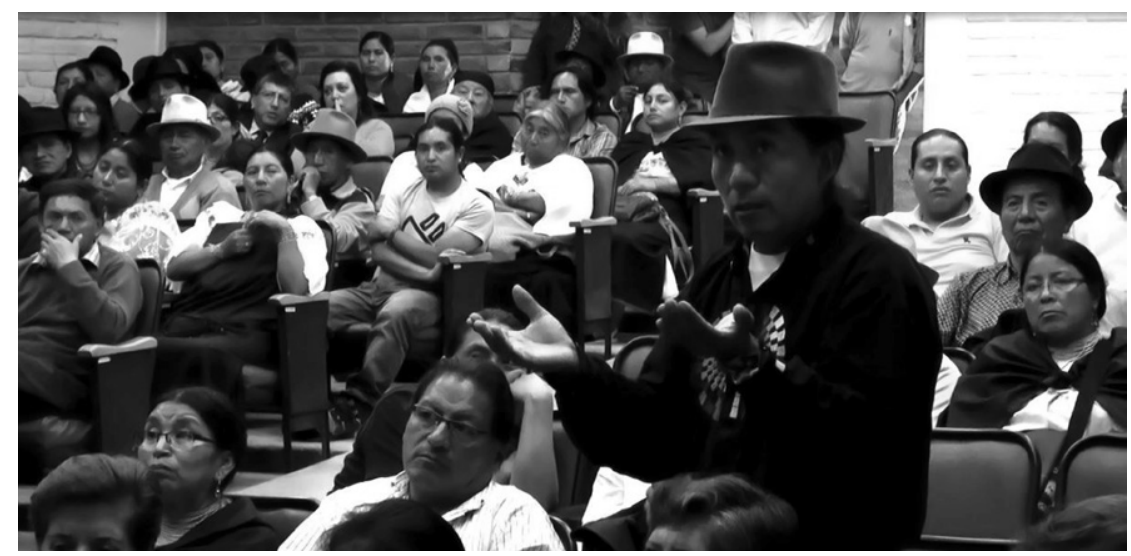

Siguiendo esta línea, comenzamos a entender que había una necesidad, por parte de los comerciantes y artesanos no representados, de verbalizar sus problemas. Y es aquí donde el investigador "neutral" y "cuasiobjetivo" se puede tornar en parte fundamental del discurso y es consciente de su propia subjetividad como herramienta metodológica de entrada en el campo y de elaboración posterior del discurso.

A partir de estos problemas, la cámara se convirtió en mediadora entre las necesidades de los vendedores y artesanos y el discurso de los go- 
bernantes locales, trasladando las reflexiones desde los unos a los otros, y viceversa.

Una vez finalizado el proceso de grabación, volvimos a España y, a lo largo de un periodo de un año, editamos el material según una idea: no incluir nuestra voz en off. Partiendo de la noción de que si el objetivo es devolver el trabajo al colectivo representado para plantear posteriores debates, y teniendo en cuenta nuestro origen español que rememora en el kichwa la represión sufrida por este pueblo en época colonial, consideramos lo más oportuno fragmentar el discurso de forma colectiva, de modo que la explicación partiera de la voz de los implicados, lo cual obliga a desmenuzar los discursos a partir de categorías temáticas, que acrecientan la intervención del realizador/antropólogo en el resultado final.

Asumimos que todo texto extraído del trabajo de campo es un relato que surge de la intersubjetividad y que, por ello, la autoría es compartida en una relación de horizontalidad que debe ser expresada en un lenguaje comprensible para los participantes. Es aquí donde el lenguaje cinematográfico posee una baza inmejorable para llevar a cabo una antropología compartida, una antropología de orientación pública. ${ }^{8}$ Compartimos con algunos antropólogos la defensa de que nuestra disciplina, la antropología, "se ha desarrollado mediante la formulación de un lenguaje elaborado, técnico, específico, especialmente limitado a su consumo por parte de otros antropólogos. Ericksen (2006) ha anotado agudamente que la antropología se ha desarrollado de manera autocontenida y elitista" (Gimeno, 2008, p. 248). Efectivamente, somos de la opinión de que

deberíamos tener una presencia pública más consistente, comunicándonos de manera que pudiéramos llegar a una audiencia más amplia. Para ello, podríamos utilizar un lenguaje diferente, seleccionando mejor las expresiones y los términos que utilizamos, no simplificando nuestras ideas, sino traduciéndolas al tener en cuenta el tipo de audiencias y medios con el que queremos comunicarnos. Donde se lee "escribir" y "hablar" debiera leerse también hacer pelí-

8 Para Gimeno, “'Antropología de orientación pública' debiera ser un término que nos ayudara a desbordar la tradicional distinción entre 'teoría' y 'aplicación. Es diferente de la antropología aplicada y también de una antropología estrictamente académica (pero hace uso de ambas)” (2008, p. 250). 
culas, fotografías y utilizar cualquier medio de expresión que pudiera trasladar nuestras aportaciones en la comprensión compleja ("densa") del mundo complejo en el que vivimos (Gimeno, 2008, p. 248).

Además, esa narrativa que debe brotar del equilibrio de fuerzas y que, de este modo, ampara la mirada del "otro", requiere que esta se presente formalmente en un código lingüístico asequible al receptor, al contrario supone una apropiación de un texto que nace de la cooperación, que surge de la ayuda mutua y que debe tener contrapartida para todos aquellos que lo generan.

Una vez finalizado el montaje en 2013, se realizaron diversas proyecciones en España y se entablaron debates con los asistentes. Salvando las diferencias culturales, la intención era probar el grado de legibilidad que tenía el texto audiovisual y las reacciones que producía en la audiencia como tentativa antes de proyectarlo en el contexto otavaleño (figura 4).

\section{Figura 4. Autoimagen grabando en la plaza de Los Ponchos (Otavalo, Ecuador, 2014)}

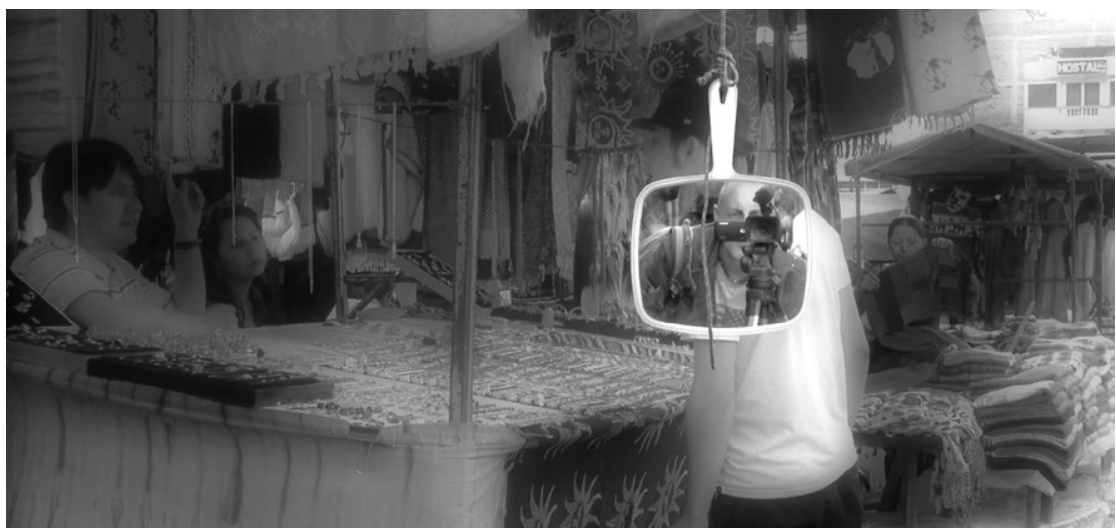

Y, partiendo de esta premisa, volvimos dos años después, en 2014, al Ecuador con el documental sobre la plaza de Los Ponchos, y que denominamos La ventana de los Andes, el cual mostraba la relevancia de este lugar como ícono cultural, político y económico, así como la reivindicación de los actores implicados en la plaza frente a la dejadez de autoridades y líderes de asociaciones (figura 5). 
Figura 5. Prefecto de Imbabura, Pablo Jurado hablando con los artesanos y comerciantes tras la proyección (Otavalo, Ecuador, 2014)

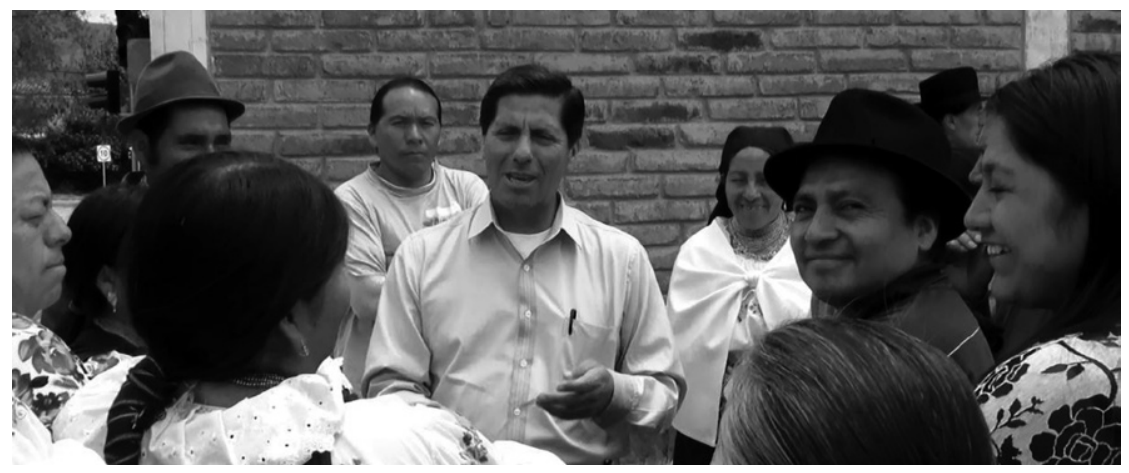

El resultado de las proyecciones que llevamos a cabo logró reabrir el debate de la necesidad de protección de la artesanía y la mejora de la situación de los vendedores y de la propia la plaza de Los Ponchos, lo cual pudimos observarlo a través de diferentes medios y publicaciones locales que se empezaban a hacer eco de las inquietudes de los comerciantes y artesanos (figura 6).

Figura 6. Los medios de comunicación se hacen eco de las necesidades de los artesanos y comerciantes (Otavalo, Ecuador, 2014)

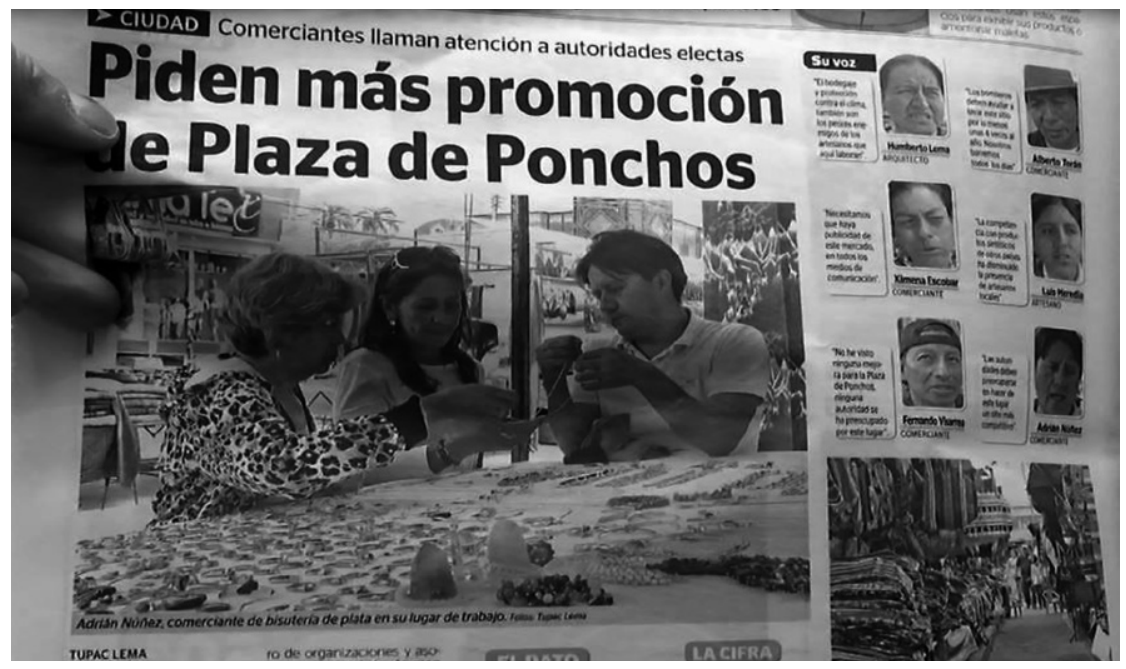


Por primera vez, no solo, artesanos, vendedores y autoridades se sentaban en un mismo espacio a discutir sobre las reformas necesarias para mejorar la plaza, sino que el Ejecutivo local se comprometió a realizar un proyecto que contemplara las necesidades verbalizadas por los comerciantes y artesanos.

Además, la proyección del documental dio lugar a una autorreflexión por parte del colectivo de la plaza de los Ponchos, que hasta entonces delegaba la resolución de sus conflictos a las posibles intervenciones del Ejecutivo local. Nos afirmaba un comerciante y artesano de la plaza: "el documental nos muestra lo que somos y hacia dónde podemos caminar, pero esto no será posible si no logramos ponernos de acuerdo. Al final, depende de nosotros". Esta afirmación nos remite a la necesidad de un empoderamiento como primer paso hacia la mejora de sus condiciones. La proyección de la imagen del grupo a través del audiovisual los empuja a tomar conciencia de la necesidad de superar discordancias puntuales en favor de un consenso de mínimos.

A su vez, la presencia de las reivindicaciones de los artesanos y comerciantes en un soporte como el audiovisual que posee una gran capacidad de divulgación parece incrementar la presión sobre los poderes locales y los medios de comunicación.

Por otro lado, si en un principio el problema principal que se denunciaba era la necesidad de una mejora de las infraestructuras del mercado, tras la proyección se incorpora al debate la necesidad de plantear la renovación de la plaza desde la perspectiva identitaria, de la cosmovisión propia del kichwa-otavaleño.

Las apreciaciones empleadas para definir el documental pueden servir como medida para valorar la repercusión del audiovisual entre autoridades, ciudadanos y artesanos de Otavalo:

Este documental va a ser un insumo para generar un debate académico, de organización (José Quimbo, concejal de urbanismo de Otavalo). 
Fue muy importante porque estuvieron presentes las autoridades y pudieron sentir de cerca las necesidades de los artesanos y nos ayuda a retomar el debate sobre la plaza y pensar qué podemos hacer (Raúl Amaguaña, presidente del Cabildo Kichwa de Otavalo).

Ver el documental nos compromete a todos los otavaleños a hacer algo por esa plaza (Gabriela Jaramillo, viceprefecta de Imbabura).

Así pues, tanto el documental Elche toma la calle sobre el movimiento $15-\mathrm{M}$ como el documental La Ventana de los Andes sobre la plaza de los Ponchos contribuyeron a que los colectivos se repensaran como grupo, tomaran conciencia identitaria, dando un paso hacia la superación de las tensiones que cerraban los posibles canales de comunicación entre las partes implicadas y a reposicionarse como grupo de referencia en el marco local en el que se desenvolvían, tal y como pudimos comprobar.

\section{Conclusiones}

La extensa literatura en torno al debate de las diferentes problemáticas asociadas al uso de equipos audiovisuales como medio para captar la realidad social se ha centrado mayoritariamente en binomios, tales como subjetivo/objetivo, realidad/ficción, arte/ciencia. Estos ejes de discusión han relegado y eclipsado uno de los aspectos más importantes: el objetivo de una obra de arte/científica, con discursos cercanos a la realidad/ficción que resalten lo objetivo/subjetivo, se encuentra condicionada por aspectos deontológicos y éticos que obligan al autor/realizador a entender que el filme con carácter social es un acto compartido, un acto de comunicación, es un fenómeno que surge de la interacción y que conlleva, implícitamente, un pacto entre aquel que registra y aquellos que son registrados.

En esta línea, cuando John y Malcom Collier (1986) realizaron un trabajo de campo, precisamente con los artesanos otavaleños, comprendieron que hay aspectos que durante la observación en el campo no son percibidos. En su caso, tras grabar la labor de un indígena en un telar, decidieron mostrárselo. El artesano les sugirió volver a grabar el proceso, pues había ciertos aspectos que ellos desconocían y que habían sido obviados. Por tanto, el resultado de aquella investigación se nutría de la mirada compartida. 
Pero, al margen del uso o no de la elicitación a la que hacen mención los Collier, el mero hecho de mantener indefinidamente en un soporte la imagen de una persona, con la posibilidad de proyectarla para que otros desconocidos lo vean, implica poner en duda la autoría de la misma investigación audiovisual.

Este pacto trasciende el concepto de 'obra de arte/científica' entendida desde la perspectiva solo y exclusivamente desde aquel que controla el proceso de producción, ya que en él intervienen personas, seres humanos y no meros elementos que se imbrican dentro del filme para configurar el universo de discurso de su autor/investigador.

Esta perspectiva endogámica que ensalza la figura del autor o de la obra científica como vía hacia un conocimiento de lo social implica una posición aséptica con respecto a la realidad social que se registra.

El realizador/investigador tiene ante sí la posibilidad de devolver a quienes han prestado su imagen y su realidad el fruto de un trabajo compartido. Es más, dado el potencial empático que posee el audiovisual, se puede llegar a configurar como una herramienta hacia el empoderamiento social.

Existe múltiples ejemplos que corroboran esta afirmación, como advierte Ana Martínez (2007) y registra Sarah Pink en su obra Visual Interventions: Applied Visual Anthropology (2009) en la que recopila diferentes casos de investigaciones etnográficas con el uso de las herramientas visuales como un modo de intervención social:

\begin{abstract}
Video allowed us to produce and reproduce a series of images that created a polyphonic representation of people who live in areas of exclusion and of their dreams. This provided us with a basis for developing awareness and reflection among the general public and, because we made our objective to reveal the reality of social exclusion, for other social workers and researchers documentary demonstrates a novel form of intervention (Martínez, 2007, p. 229, citado en Pink, 2009).
\end{abstract}

Esta novedosa forma de intervención implica, necesariamente, trascender las limitaciones que desde cierta antropología audiovisual se han 
impuesto al uso de los recursos audiovisuales. Y es que en la actualidad asistimos a una expansión de posibilidades sin precedente para la antropología audiovisual ante las nuevas tecnologías de la información y la comunicación y el mundo digital y virtual. Como advirtiera Sarah Pink (2006), el siglo XXI ha encontrado a la antropología visual en un lugar privilegiado para la investigación.

Necesitamos del potencial artístico expresado con el lenguaje audiovisual para devolver el fruto del conocimiento adquirido a quienes nos lo han proporcionado. Sin esta devolución, estamos haciendo un arte, una ciencia, que no está al servicio de la gente, sino que reproduce, indirectamente, el discurso de un sistema mundo que aleja, cada vez más, de sí a las personas, y que da prioridad a productos sobre ciudadanos.

\section{Referencias}

Adame C., M. A. (2010). Antropología, marxismo y compromiso social. En Rebelión. Recuperado el 22 de diciembre de 2014 de http:// www.rebelion.org/noticia.php?id=107843

Ardèvol, E. (1994). La mirada antropológica o la antropología de la mirada. Barcelona: Editorial Universidad Autónoma de Barcelona.

Ardévol, E. (1998). Por una antropología de la mirada: etnografía, representación y construcción de datos audiovisuales. Revista de Dialectología y Tradiciones Populares, 53(2), 217-240.

Ardèvol, E. (2004). Visualidad y mirada. El análisis cultural de la imagen. En E. Ardèvol y N. Muntayola, (coords.), Representación y cultura audiovisual en la sociedad contemporánea (pp. 17-46). Barcelona: Editorial de la Universitat Oberta de Catalunya.

Ardévol, E. (2008). Cine etnográfico: relato, discurso y teoría. Documentos CIDOB. Dinámicas interculturales, 12, 31-49. 
Asch, T. (1992). Del cine y la antropología. Gazeta de Antropología, 9, 1-6.

Buitrón, A. (1971). El valle del amanecer. Instituto Otavaleño de Antropología.

Caicedo, A. (2003). Aproximaciones a una antropología reflexiva. Tabula Rasa, 1, 165-181.

Canals, R. y Cardús, L. (2010). De la imagen como huella a la imagen como encuentro. Revista Chilena de Antropología Visual, 15, 22-39.

Collier, J. y Collier, M. (1986). Visual anthropology: Photography as a research method. Nuevo México: UNM Press.

Contreras, R., Donoso, J. P. y Pineda, M. (2004). ¿Comunicación para el desarrollo? O cómo usar la antropología audiovisual en la construcción de comunicación local. En Actas $5^{\circ}$ Congreso Chileno de Antropología Simposio Antropología Visual (t. I, pp.143-151). San Felipe, Chile.

Dufuur, L. (2010). Tendencias actuales del cine-documental. Frame, 6, 312-349.

Ericksen, T. H. (2006). Enganging anthopology: The case for a public presence. Oxford, Nueva Yok: Berg Publisher.

Galán Zarzuelo, M. (2012). Cine militante y videoactivismo: los discursos audiovisuales de los movimientos sociales. Comunicación: Revista Internacional de Comunicación Audiovisual, Publicidad y Estudios Culturales, 10, 1091-1102.

Gimeno, J. C. (2008). Antropología(s) de orientación pública: 'asomarse unos centímetros más allá del borde, ahí donde la perspectiva se amplía ligeramente.' En M. J. Velasco, P. M. Requena y P. P. Chamoro, Antropología de orientación pública: visibilización y compromiso de la Antropología (pp.247-275). Ankulegi Antropologia Elkartea. 
Gramsci, A. (1984). La formación de los intelectuales. México: Grijalbo.

Grau Rebollo, J. (2005). “Los límites de lo etnográfico son los límites de la imaginación”. El legado fílmico de Jean Rouch. AIBR: Revista de Antropología Iberoamericana, 41, 5.

Instituto Nacional de Estadística. (s. f.). Cifras oficiales de población resultantes de la revisión del padrón municipal a 1 de enero. Recuperado el 25 de enero de 2015 de http:/ /www.ine.es/jaxiT3/Datos. htm?t=2856

Heider, K. G. (2009). Ethnographic film: Revised edition. University of Texas Press.

Houtart, F. (2013). El bien común de la humanidad. Quito: Editorial IAEN.

Lisón Arcal, J. C. (1999). Una propuesta para iniciarse en la antropología visual. Revista de Antropología Social, 8, 15-35.

MacDougall, D. y Taylor, L. (1998). Transcultural cinema. Princeton University Press.

Martínez Pérez, A. (2007). The rhythm of our dreams: a proposal for an applied visual anthropology. Visual interventions. En S. Pink, Visual interventions: Applied visual anthropology (pp. 227-246). Oxford: Berghahn.

Mestman, M. (2001). La exhibición del cine militante. Teoría y práctica en el Grupo Cine Liberación. En Actas del VIII Congreso de la Asociación Española de Historiadores de Cine. Madrid.

Nichols, B. (1997). La representación de la realidad: cuestiones y conceptos sobre el documental. Barcelona: Paidós.

Pink, S. (2006). The future of visual anthropology: Engaging the senses. Taylor \& Francis. 
Pink, S. (2009). Visual interventions: Applied visual anthropology. Berghahn Books.

Ruby, J. (2007). Los últimos 20 años de Antropología visual: una revisión crítica. Revista Chilena de Antropología Visual, 9, 13-36.

Santos, B. de S (2005). El milenio huérfano. Ensayos para una nueva cultura política. Madrid: Trotta.

Stoehrel, V. (2003). Cine sobre gente, gente sobre cine. Entre el documental televisivo y el académico". Revista Virtual Razón y Palabra. Recuperado el 25 de enero de 2015 de http://www.razonypalabra. org.mx/libros/libros/cine-gente.pdf

Wallerstein, I. (1999). La formación de los intelectuales. Madrid: Siglo XXI. 